\title{
Carotid endarterectomy versus carotid angioplasty for stroke prevention: a systematic review and meta-analysis
}

\author{
Zengyan Diao, Guoyong Jia, Wei Wu and Cuilan Wang ${ }^{*}$
}

\begin{abstract}
Background: This meta-analysis aimed to evaluate the efficacy of carotid endarterectomy (CE) compared with carotid angioplasty (CA) in preventing stroke. Whether the use of CE is more efficient in preventing stroke than $\mathrm{CA}$ is a matter of debate.

Methods: Data were gathered from randomized controlled trials to evaluate the effect of CE compared with CA on the risk of stroke. Electronic searches in PubMed, Embase, and the Cochrane Library were performed to identify studies till November 2014. Only randomized controlled trials performed on patients who received either CE or CA for stroke prevention were included.

Results: Nine relevant trials $(n=7163)$ that met the inclusion criteria were identified. In a pooled analysis, CE resulted in $35 \%$ reduction in relative risk (RR) for short-term stroke [RR, $0.65 ; 95 \%$ confidence interval (Cl): $0.47-0.89 ; P=0.007)]$ and $22 \%$ reduction in RR for long-term stroke (RR, $0.78 ; 95 \% \mathrm{Cl}: 0.66-0.93 ; P=0.006$ ) relative to CA. However, CE also increased the risk of 30-day myocardial infarction by $114 \%$ compared with CA $(\mathrm{RR}, 2.14 ; 95 \% \mathrm{Cl}: 1.30-3.53 ; P=0.003)$. Sensitivity analyses suggested that $C E$ might influence the risk of 30-day major vascular events and 1-year major vascular events compared with CA.

Conclusions: CE could reduce the risk of stroke (whether short term or long term), but resulted in a relative increase in the risk of myocardial infarction. This study might guide appropriate judgments about treatment approach. It also provided evidence to justify general guidelines for patients with carotid artery stenosis.
\end{abstract}

Keywords: Carotid angioplasty, Carotid endarterectomy, Meta-analysis

Abbreviations: CA, Carotid angioplasty; CE, Carotid endarterectomy; Cls, Confidence intervals; RR, Relative risk

\section{Background}

Cerebrovascular disease, either ischemic or hemorrhagic stroke, is the leading cause of premature mortality and morbidity worldwide for both men and women [1-3]. Asian countries have a higher incidence of stroke compared with Western countries [4]. Over the past few years, many studies have shown a strong correlation between carotid artery stenosis and stroke $[5,6]$. It has been suggested that carotid artery stenosis should be corrected as a therapeutic approach to prevent stroke events. However, the use of carotid endarterectomy (CE)

\footnotetext{
* Correspondence: wclsci@163.com

Department of Neurology, Qilu Hospital of Shandong University, Jinan 250012, Shandong Province, China
}

\section{Biomed Central}

compared with carotid angioplasty (CA) for preventing stroke has not been shown consistently to be beneficial.

CE was recommended as the standard therapy, which could reduce the risk of stroke in patients with carotid artery stenosis [7]. However, in many cases, a high residual risk of stroke persists after CE. Hence, it is necessary to explore additional effective preventive therapies [8]. Recently, endovascular treatments [9] (CA with or without stenting) have been increasingly used as an alternative to CE. However, whether endovascular treatments are more effective than surgery in patients with carotid artery stenosis remains unclear. This led to uncertainty over the presence and magnitude of any protective effects of endovascular treatments and surgery on stroke, and also difficulties in interpretation of the results. Therefore, this 
systematic review and meta-analysis was conducted to evaluate the possible effect of CE compared with CA on stroke in patients with carotid artery stenosis.

\section{Methods}

Data sources, search strategy, and selection criteria

This review was conducted and reported according to the Preferred Reporting Items for Systematic Reviews and Meta-Analysis Statement [10] issued in 2009. Data were gathered from randomized controlled trials to evaluate the effect of $\mathrm{CE}$ compared with $\mathrm{CA}$ on the risk of stroke. Trials comparing CE with CA were included, excluding any studies with a sample size less than 50 , to alleviate systematic error and resulting bias, hence ensuring the reliability of the conclusion.

The English literature was systematically searched to identify all relevant randomized, controlled trials regardless of publication status (published, in press, and in progress). Relevant trials were identified using the following procedures:

(1)Electronic searches: The PubMed, Embase, and the Cochrane Central Register of Controlled Trials were searched for randomized controlled trials of $\mathrm{CE}$ compared with CA, using "endarterectomy,", "angioplasty," "stenting," stenosis," "carotid," "human," "English,", and "randomized controlled trials" as search terms. All reference lists from reports on nonrandomized controlled trials were searched manually for additional eligible studies.

(2)Other sources: Authors were contacted to obtain any possible additional published or unpublished data, and the site http://www.ClinicalTrials.gov was searched for ongoing randomized controlled trials that had been registered as completed but not yet published, using the aforementioned terms. Medical subject headings, methods, patient populations, interventions, and outcome variables of these studies were used to identify relevant trials.

The literature search, data extraction, and quality assessment were undertaken independently by two authors ( $\mathrm{CZ}$ and FLC) using a standardized approach, and any discrepancy was settled by group discussion. Studies were eligible for inclusion if: (1) the study was a randomized controlled trial; (2) sample size was more than 50 ; (3) the number of events for stroke that occurred during the study was more than 10 ; (4) the trials assessed the effects of CE compared with CA; and (5) patients had carotid artery stenosis.

\section{Data collection and quality assessment}

All data from eligible trials were independently abstracted in duplicate by two independent investigators $(\mathrm{CZ}$ and
FLC) using the standard protocol, and reviewed by a third investigator $(\mathrm{AJH})$. Any discrepancy was resolved by group discussion. Data were extracted from the included trials were as follows: name of first author or study group, publication year, number of patients, percentage of males, mean age, history of disease, intervention, control, duration of follow-up, and primary outcome (the number of incident cases for each treatment group). One author (AJH) entered the data into computer, and the primary author (YHZ) checked it. The study quality was assessed using the Jadad score [11], which was based on the following five subscales: randomization ( 1 or 0$)$, concealment of the treatment allocation ( 1 or 0$)$, blinding ( 1 or 0$)$, completeness of follow-up ( 1 or 0 ), and the use of intention-totreat analysis ( 1 or 0$)$. A "score system" (ranging from 0 to 5) was developed for assessment. In this meta-analysis, a study with a score of 4 or more was considered to be of high quality.

\section{Statistical analysis}

The results of each randomized controlled trial was compiled as dichotomous frequency data. Individual study relative risks (RRs) and $95 \%$ confidence intervals (CIs) were calculated from event numbers extracted from each trial before data pooling. The overall RR and $95 \%$ CIs of stroke incidence, major vascular events, myocardial infarction, and any possible adverse events were also calculated. Both fixed-effects and randomeffects models were used to assess the pooled RR for CE compared with CA. Although both models yielded similar findings, the results from the random-effects model assumed that the underlying effect varied among included trials $[12,13]$. The heterogeneity of the treatment effects between studies was investigated visually using scatter plot analysis as well as statistically using the heterogeneity $\mathrm{I}^{2}$ statistic $[14,15]$. A sensitivity analysis was also performed by removing each individual trial from the meta-analysis. An Egger's test [16] was used to check for potential publication bias. All the reported $P$ values were two-sided, and a $P$ value less than 0.05 was regarded as statistically significant for all included studies. All analyses were calculated using software STATA (version 10.0).

\section{Results}

Of the 19 trials retrieved for detailed assessment, 10 were excluded because: they lacked data on stroke, they reported on the same study population, [17] they were of small sample size, or it was a stopped trial. The final analysis included nine randomized controlled trials [18-26] consisting of 7163 patients with carotid artery stenosis (Fig. 1). These trials compared CE with CA, with stroke reported as one of the endpoints. Table 1 summarizes the characteristics of these trials and the important baseline 


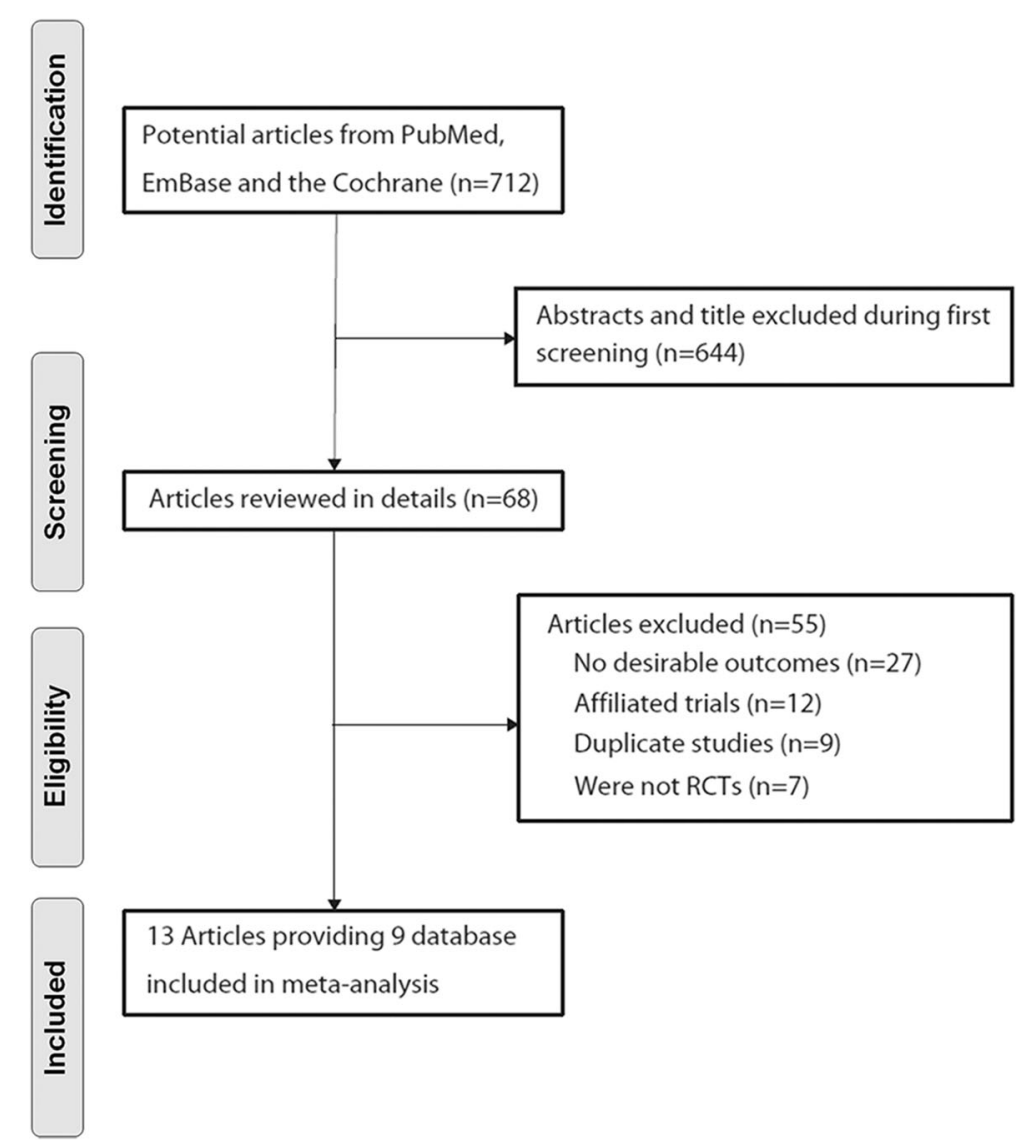

Fig. 1 Flow diagram of the literature search and trials selection process

information of the included 7163 patients. Of the nine trials, two were performed in the USA [18, 20], four in European countries [19, 21, 22, 24], one [23] in Germany, Austria, and Switzerland, one [25] in the USA and Canada, and one [26] in Europe, Australia, and Canada. The number of patients ranged from 87 to 2502 . The percentage of previous cases with cardiovascular disease ranged from 11.9 to $80.7 \%$. The duration of follow-up ranged from 0.3 to 5.4 years. The inclusion criteria were restricted to randomized controlled trials with the number of patients more than 50 to ensure that high-quality literature was included in the study. Although the included trials scarcely reported on the key indicators of trial quality, the quality of the included trials was also evaluated according to the predefined criteria using the Jadad score [11]. Overall, five [20-23, 25] of the included trials scored 4 , two trials $[19,26]$ scored 3 , and the remaining two trials $[18,24]$ scored 2.

Data on the effect of CE on 30-day major vascular events were available from 7 trials, which included 6911 patients and reported 424 major vascular events. Figure 2 shows the effect of $\mathrm{CE}$ on 30-day major vascular events compared with CA. The pooled RR showed a $22 \%$ reduction in 30-day major vascular events, but with no evidence showing that $\mathrm{CE}$ protected against the risk of vascular events (RR, 0.78; $95 \% \mathrm{CI}: 0.57-1.06 ; P=0.11$ ). Some evidence of heterogeneity across the studies included was available. A sensitivity analysis indicated that $\mathrm{CE}$ was associated with a reduction in the risk of 30-day major vascular events, which was decreased by $28 \%$ (RR, 0.72; 95 \% CI: 0.54-0.94; $P=0.02$, Fig. 2) when excluding SAPPHIRE trials [18]. This trial specifically added an embolic protection device to carotid artery stenting, which was more efficient in preventing major vascular events. Similarly, no evidence was found to show that CE protected against 1-year/within 1-year major vascular events (RR, $0.69 ; 95 \% \mathrm{CI}: 0.40-1.18 ; P=0.18$, Fig. 2). Substantial heterogeneity was observed in the magnitude of the effect across the trials included, according to a sensitivity analysis. It was concluded that $\mathrm{CE}$ was associated with a reduction in the risk of 1-year/ within 1-year major vascular events, which was decreased by $44 \%$ (RR, 0.56; $95 \%$ CI: 0.42-0.75; $P<0.001$, Fig. 2 ) when excluding SAPPHIRE trials [27]. Finally, the pooled analysis showed no significant differences in the influence of $\mathrm{CE}$ and $\mathrm{CA}$ on long-term (more than 1-year) major vascular events (RR, 1.00; $95 \% \mathrm{CI}: 0.87-1.14 ; P=0.95$, Fig. 2). 


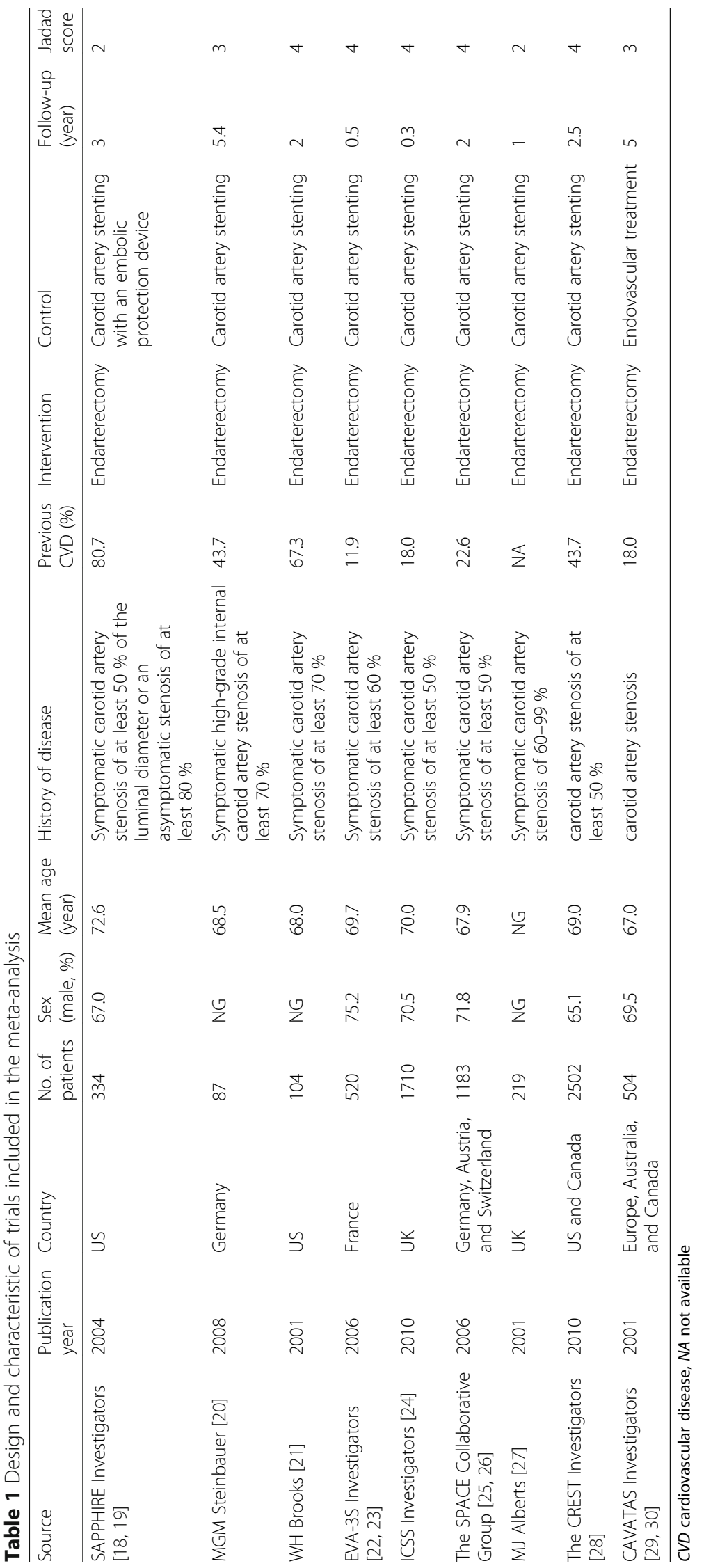




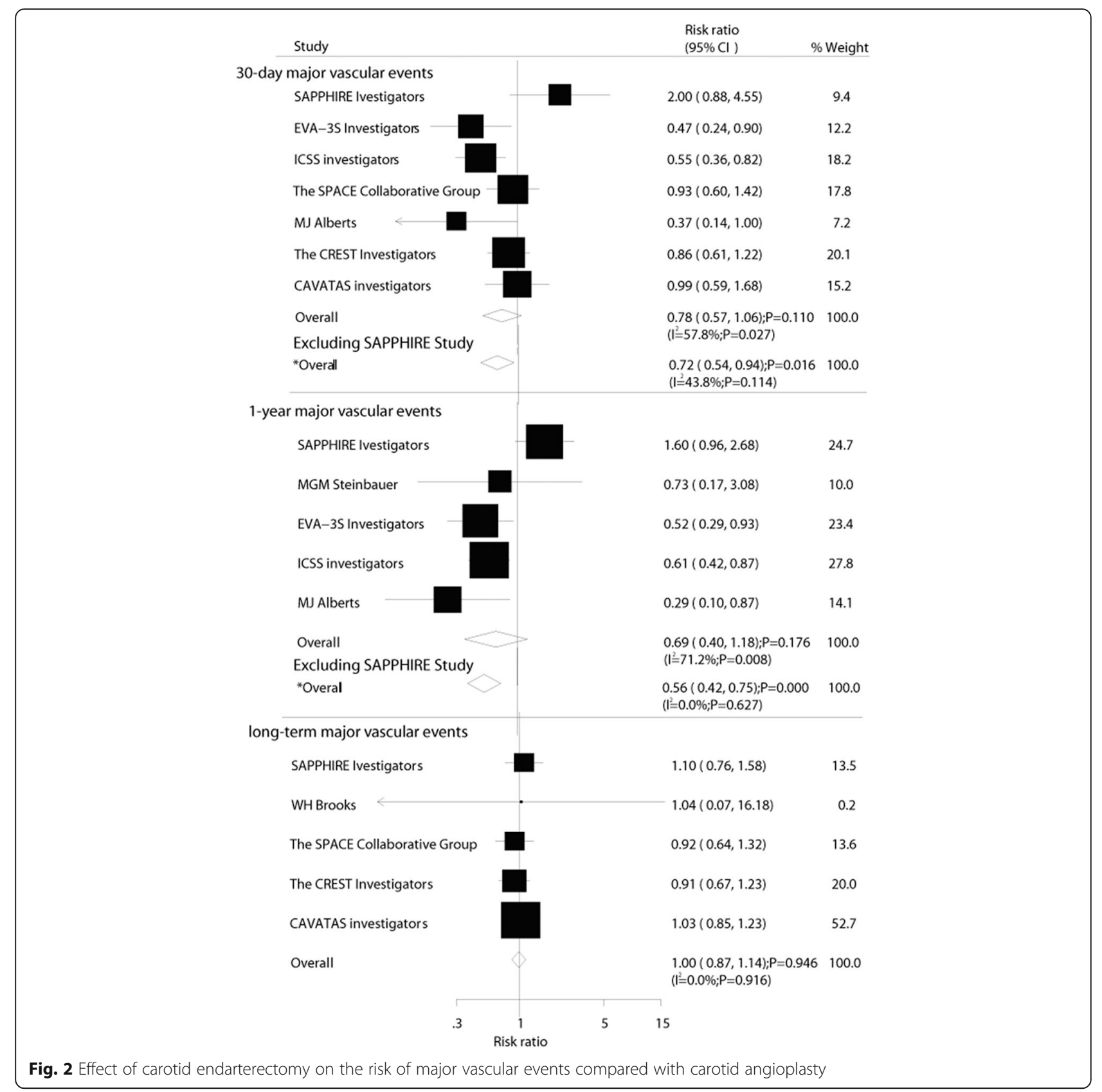

Data on the effect of CE on 30-day stroke were available from 6 trials, including 6692 patients and 330 events of stroke. Overall, CE resulted in a $35 \%$ reduction in the risk of 30-day stroke compared with CA (RR, 0.65; 95 \% CI: 0.47-0.89; $P=0.007$, Fig. 3). Despite some evidence of heterogeneity across the studies included, a sensitivity analysis indicated that the results were not affected by sequential exclusion of any particular trial from the pooled analysis. Furthermore, although CE reduced the risk of 1-year/within 1-year stroke by $36 \%$, it was not associated with a statistically significant difference (RR, 0.64; 95 \% CI: 0.39-1.04;
$P=0.07$, Fig. 3). A sensitivity analysis indicated that $\mathrm{CE}$ was associated with a reduction in the risk of 1-year/ within 1-year stroke, which was decreased by $48 \%$ (RR, 0.52; 95 \% CI: 0.35-0.76; $P=0.001$, Fig. 3) when excluding SAPPHIRE trials [27]. Finally, when patients received CE, the risk of long-term stroke was significantly reduced by 22 \% compared with CA (RR, 0.78; 95 \% CI: 0.66-0.93; $P=0.006$, Fig. 3).

Data for the effect of CE on 30-day mortality were available from 6 trials, which included 6692 patients and reported 59 events of death. No effect of CE on the risk of 30-day mortality was observed (RR, 0.70; 95 \% CI: 


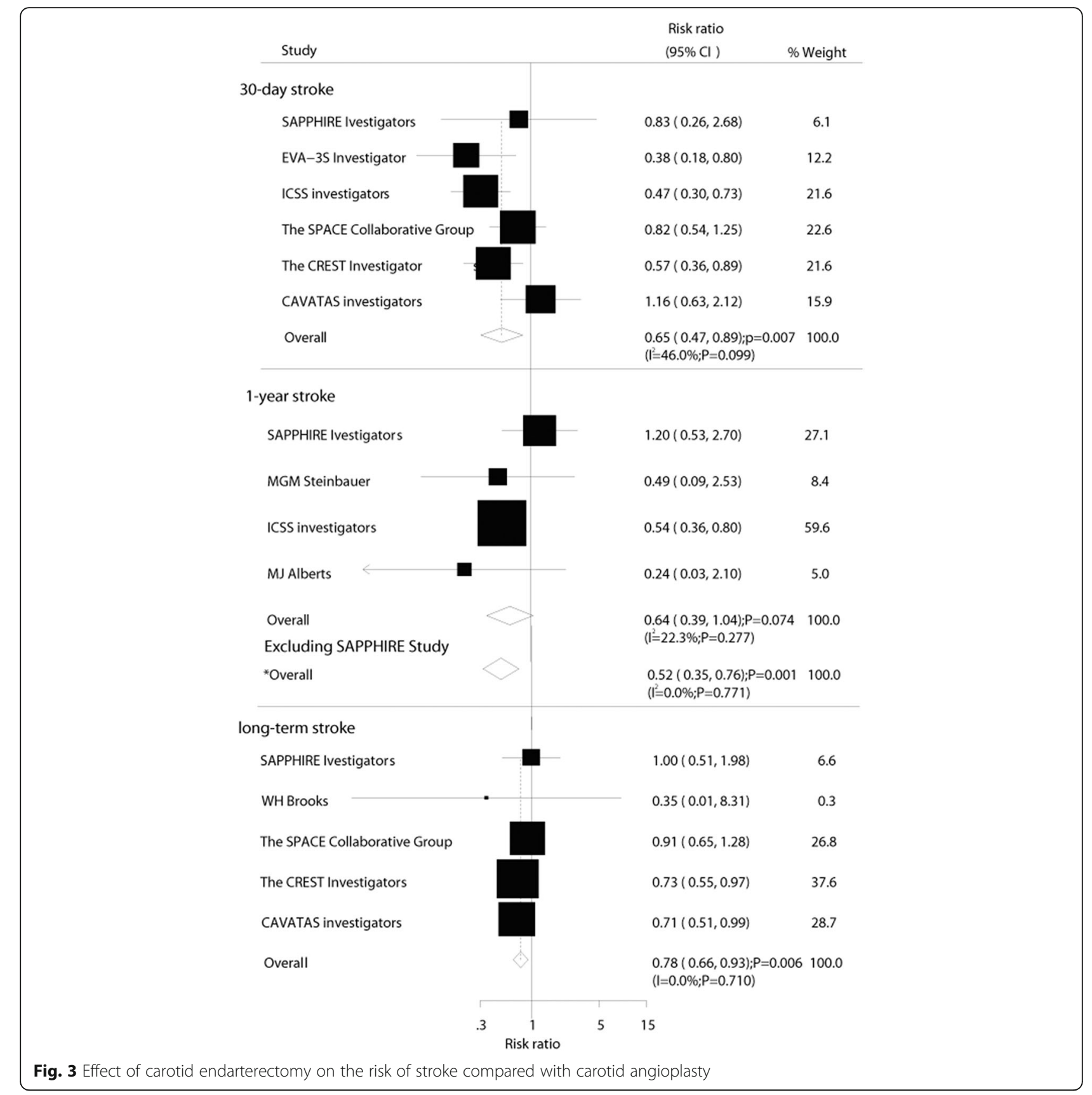

$0.41-1.21 ; P=0.20$, without evidence of heterogeneity, Fig. 4). Similarly, no evidence was found to show that $\mathrm{CE}$ could reduce the risk of 1-year/within 1-year mortality (RR, 0.82; 95 \% CI: $0.18-3.81 ; P=0.80$, Fig. 4) and longterm mortality (RR, $0.98 ; 95 \% \mathrm{CI}: 0.85-1.13 ; P=0.78$, without evidence of heterogeneity, Fig. 4).

The effect of CE on the risk of 30-day myocardial infarction was reported in 5 trials, which included 5509 patients and recorded 70 events of myocardial infarction. Overall, it was noted that CE increased the risk of 30day myocardial infarction by $114 \%$ compared with CA (RR, 2.14; 95 \% CI: 1.30-3.53; $P=0.003$; Fig. 5). Only three trials provided data on 1-year/within 1-year myocardial infarction. It was noted that $\mathrm{CE}$ increased the risk of 1-year/within 1-year myocardial infarction by $104 \%$, but it was not associated with a statistically significant difference (RR, 2.04; 95 \% CI: 0.90-4.61; $P=0.09$, Fig. 5). Furthermore, only SAPPHIRE trials [27] provided data on long-term myocardial infarction. No effect of CE on the risk of long-term myocardial infarction events was observed (RR, 1.56; 95 \% CI: 0.69-3.49; $P=0.28$ ).

Egger test [16] was used to check for potential publication bias, which showed no evidence of publication bias for the outcomes of 30-day major vascular events 


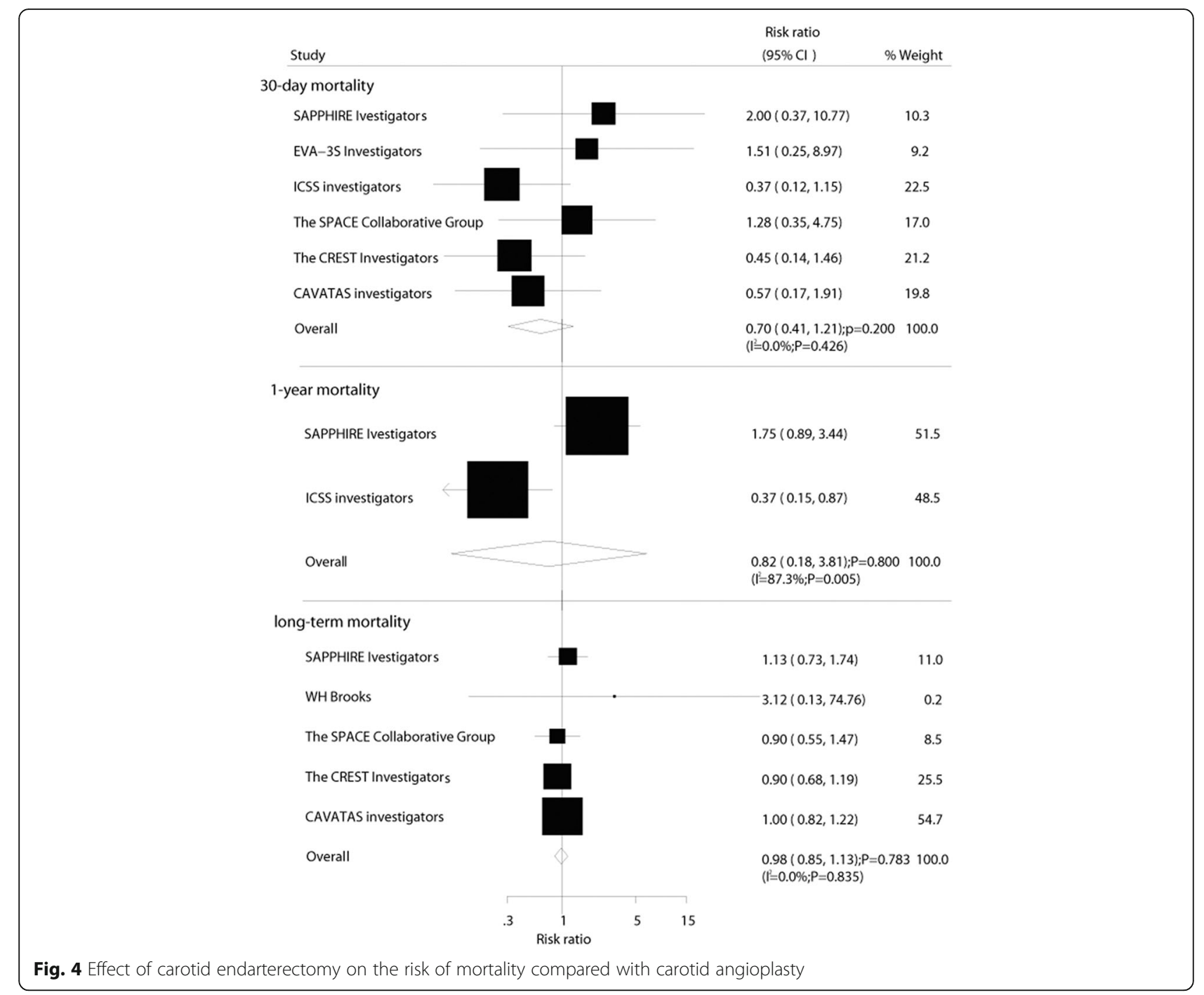

$(P$ value for Egger test, 0.889$), 30$-day stroke ( $P$ value for Egger test, 0.902), and 30-day myocardial infarction $(P$ value for Egger test, 0.376). However, evidence was found of publication bias for 30 -day mortality ( $P$ value for Egger test, 0.025). The conclusions were not changed after adjustment for publication bias using the trim-and-fill method [28].

\section{Discussion}

A direct relationship was observed between the degree of carotid artery stenosis and the risk of stroke. Although $\mathrm{CE}$ has been considered the gold standard for the treatment of carotid stenosis for decades, evidence from largescale randomized controlled trials [6] has shown that CA has emerged as an alternative therapy for this common disorder. The results of this meta-analysis showed that CE reduced the risk of 30-day stroke and long-term stroke. However, it also significantly increased the risk of myocardial infarction compared with CA. Furthermore, sensitivity analyses suggested that CE might influence the risk of 30day and 1-year/within 1-year major vascular events.

According to the SAPPHIRE trials [18, 27], the study suggested that $\mathrm{CA}$ was not inferior to $\mathrm{CE}$ in preventing the risk of stroke, whether short term or long term. The present results were inconsistent with large-scale randomized, controlled trials, probably because this trial specifically added an embolic protection device to carotid artery stenting, which might have contributed more efficacy in preventing the risk of stroke. Furthermore, EVA-3S trials $[21,29]$ indicated that in patients with symptomatic carotid stenosis of $60 \%$ or more, the rates of death and stroke at 1 and 6 months were lower with CE than with CA. SPACE trials $[23,30]$ failed to prove the noninferiority of $\mathrm{CA}$ compared with $\mathrm{CE}$ in terms of the periprocedural complication rate. Furthermore, it suggested a similar effect on the risk of ipsilateral ischemic strokes between $\mathrm{CE}$ and CA. The present study defined that benefits could be achieved when patients with 


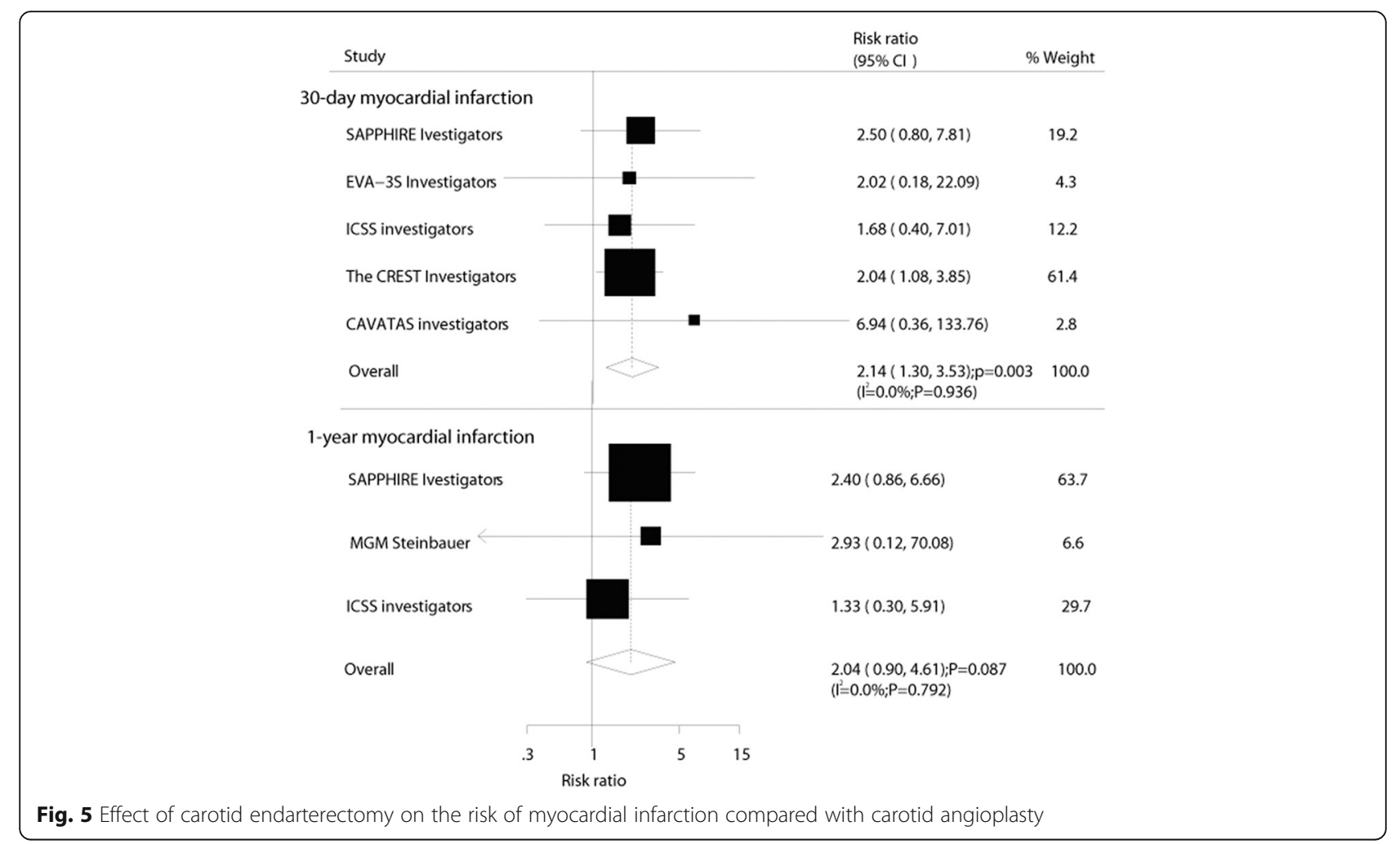

carotid artery stenosis underwent CE. However, it was also noted that $\mathrm{CE}$ significantly increased the risk of short-term myocardial infarction. The risk of 1-year/ within 1-year myocardial infarction and long-term myocardial infarction was not observed, probably because less number of trial provided data for this result.

CE might play an important role in mortality, although a significant difference was not observed. The reason for this could be that $\mathrm{CE}$ also significantly increased the risk of myocardial infarction, translating into an increased risk of life-threatening events. CAVATAS trial [26, 31] indicated that more patients had stroke during long-term follow-up in the endovascular group than in the surgical group. However, the rate of ipsilateral non-perioperative stroke was low in both the groups, with no differences in the stroke outcome measures. This conclusion was in accordance with the findings of the present meta-analysis. This study was promising because randomized controlled trials were restricted to meet the inclusion criteria, and the aim was to provide the best evidence for a causal relationship.

A previous meta-analysis [32] illustrated that carotid artery stenting was inferior to CE with regard to the incidence of stroke or death for periprocedural outcomes, especially in symptomatic patients. Furthermore, it also suggested that carotid artery stenting was associated with a lower incidence of myocardial infarction. The present study also confirmed that patients who underwent CE had a high risk of myocardial infarction. However, it also indicated that $\mathrm{CE}$ was associated with a statistically significant reduction in the risk in stroke.

The major limitation of this study was the inherent assumptions made for the meta-analysis. The analysis used pooled data, whether from published papers or provided by individual authors. Individual patient data and original data were not available, which restricted performing more detailed relevant analysis and obtaining more comprehensive results. Additionally, no sufficient data were available on detailed effects of $\mathrm{CE}$ on the risk of different types of stroke. Furthermore, during the planning stages, the intention was to perform subgroup analyses on the basis of other confounders, which might affect the treatment effect. However, the results of subgroup analyses on the basis of follow-up duration might be unreliable because of smaller cohorts included. This study attempted to provide a comprehensive review on the comparison between the efficacy of CE and CA.

\section{Conclusions}

In conclusion, $\mathrm{CE}$ could reduce the risk of stroke (whether short term or long term), and might influence the risk of major vascular events compared with CA. However, it also increased the risk of 30-day myocardial infarction. The present study might guide appropriate judgments about treatment approach. It also provided evidence to justify general guidelines for patients with carotid artery stenosis. 
It is suggested that the following factors be improved in future research: (1) the adverse effect events of clinical trials should be recorded and reported normatively and (2) myocardial infarction events should be taken into consideration for patients who underwent CE.

\section{Acknowledgments}

None.

\section{Funding}

The project was supported by Shandong Province Science and Technology Research Fund Project (2009GG20002023).

\section{Availability of data and materials}

The dataset supporting the conclusions of this article is included within the article.

\section{Authors' contributions}

ZYD and CLW contributed to conception and design; ZYD, GYJ, WW, and CLW contributed to acquisition of data, or analysis and interpretation of data; and ZYD, GYJ, WW, and CLW were involved in drafting the manuscript or revising it critically for important intellectual content. All authors have given final approval on the version to be published.

\section{Competing interests}

The authors declare that they have no competing interests.

\section{Consent for publication}

Not applicable.

\section{Ethics approval and consent to participate}

Not applicable.

\section{Received: 8 April 2016 Accepted: 23 August 2016}

Published online: 08 September 2016

\section{References}

1. Thom T, Haase N, Rosamond W, Howard VJ, Rumsfeld J, Manolio T, et al. Heart disease and stroke statistics-2006 update: a report from the American Heart Association Statistics Committee and Stroke Statistics Subcommittee. Circulation. 2006;113:e85-151.

2. Williams GR, Jiang JG, Matchar DB, Samsa GP. Incidence and occurrence of total (first-ever and recurrent) stroke. Stroke. 1999;30:2523-8.

3. Yusuf S, Reddy S, Ounpuu S, Anand S. Global burden of cardiovascular diseases: part l: general considerations, the epidemiologic transition, risk factors, and impact of urbanization. Circulation. 2001:104:2746-53.

4. Ueshima H, Sekikawa A, Miura K, Turin TC, Takashima N, Kita Y, et al. Cardiovascular disease and risk factors in Asia: a selected review. Circulation. 2008;118:2702-9.

5. Rothwell PM, Eliasziw M, Gutnikov SA, Fox AJ, Taylor DW, Mayberg MR, et al. Analysis of pooled data from the randomised controlled trials of endarterectomy for symptomatic carotid stenosis. Lancet. 2003;361:107-16.

6. Inzitari D, Eliasziw M, Gates P, Sharpe BL, Chan RK, Meldrum HE, et al. The causes and risk of stroke in patients with asymptomatic internal-carotidartery stenosis. North American Symptomatic Carotid Endarterectomy Trial Collaborators. N Engl J Med. 2000;342:1693-700.

7. Halliday A, Mansfield A, Marro J, Peto C, Peto R, Potter J, et al. Prevention of disabling and fatal strokes by successful carotid endarterectomy in patients without recent neurological symptoms: randomised controlled trial. Lancet. 2004;363:1491-502.

8. Yadav JS, Roubin GS, lyer S, Vitek J, King P, Jordan WD, et al. Elective stenting of the extracranial carotid arteries. Circulation. 1997;95:376-81.

9. Roubin GS, New G, lyer SS, Vitek JJ, Al-Mubarak N, Liu MW, et al. Immediate and late clinical outcomes of carotid artery stenting in patients with symptomatic and asymptomatic carotid artery stenosis: a 5-year prospective analysis. Circulation. 2001:103:532-7.

10. Moher D, Liberati A, Tetzlaff J, Altman DG, Group P. Preferred reporting items for systematic reviews and meta-analyses: the PRISMA statement. PLoS Med. 2009;6, e1000097.
11. Jadad AR, Moore RA, Carroll D, Jenkinson C, Reynolds DJ, Gavaghan DJ, et al. Assessing the quality of reports of randomized clinical trials: is blinding necessary? Control Clin Trials. 1996;17:1-12.

12. DerSimonian R, Laird N. Meta-analysis in clinical trials. Control Clin Trials. 1986;7:177-88

13. Ades AE, Lu G, Higgins JP. The interpretation of random-effects meta-analysis in decision models. Med Decis Making. 2005;25:646-54.

14. Deeks JJ, Higgins JPT, Altman DG. Analyzing data and undertaking metaanalyses. In: Higgins J, Green S, editors. Cochrane handbook for systematic reviews of interventions 5.0.1. Oxford: The Cochrane Collaboration; 2008.

15. Higgins JP, Thompson SG, Deeks JJ, Altman DG. Measuring inconsistency in meta-analyses. BMJ. 2003;327:557-60

16. Egger M, Davey Smith G, Schneider M, Minder C. Bias in meta-analysis detected by a simple, graphical test. BMJ. 1997;315:629-34.

17. Naylor AR, Bolia A, Abbott RJ, Pye IF, Smith J, Lennard N, et al. Randomized study of carotid angioplasty and stenting versus carotid endarterectomy: a stopped trial. J Vasc Surg. 1998;28:326-34.

18. Yadav JS, Wholey MH, Kuntz RE, Fayad P, Katzen BT, Mishkel GJ, et al. Protected carotid-artery stenting versus endarterectomy in high-risk patients. N Engl J Med. 2004;351:1493-501.

19. Steinbauer MG, Pfister K, Greindl M, Schlachetzki F, Borisch I, Schuirer G, et al. Alert for increased long-term follow-up after carotid artery stenting: results of a prospective, randomized, single-center trial of carotid artery stenting vs carotid endarterectomy. J Vasc Surg. 2008:48:93-8.

20. Brooks WH, McClure RR, Jones MR, Coleman TC, Breathitt L. Carotid angioplasty and stenting versus carotid endarterectomy: randomized trial in a community hospital. J Am Coll Cardiol. 2001;38:1589-95.

21. Mas J-L, Chatellier G, Beyssen B, Branchereau A, Moulin T, Becquemin J-P, et al. Endarterectomy versus stenting in patients with symptomatic severe carotid stenosis. N Engl J Med. 2006;355:1660-71.

22. International Carotid Stenting Study i, Ederle J, Dobson J, Featherstone RL, Bonati $\mathrm{LH}$, van der Worp HB, et al. Carotid artery stenting compared with endarterectomy in patients with symptomatic carotid stenosis (International Carotid Stenting Study): an interim analysis of a randomised controlled trial. Lancet. 2010:375:985-97.

23. Ringleb P, Allenberg J, Brückmann H, Eckstein H, Fraedrich G, Hartmann M, et al. 30 day results from the SPACE trial of stent-protected angioplasty versus carotid endarterectomy in symptomatic patients: a randomised non-inferiority trial. Lancet. 2006;368:1239-47.

24. Alberts MJ, editor. Results of a multicenter prospective randomized trial of carotid artery stenting vs. carotid endarterectomy. Abstracts of the International Stroke Conferences; 2001. Am Heart Assoc.

25. Brott TG, Hobson 2nd RW, Howard G, Roubin GS, Clark WM, Brooks W, et al. Stenting versus endarterectomy for treatment of carotid-artery stenosis. N Engl J Med. 2010;363:11-23.

26. Endovascular versus surgical treatment in patients with carotid stenosis in the Carotid and Vertebral Artery Transluminal Angioplasty Study (CAVATAS): a randomised trial. Lancet. 2001;357:1729-37.

27. Gurm HS, Yadav JS, Fayad P, Katzen BT, Mishkel GJ, Bajwa TK, et al. Longterm results of carotid stenting versus endarterectomy in high-risk patients. N Engl J Med. 2008;358:1572-9.

28. Duval S, Tweedie R. A nonparametric "trim and fill" method of accounting for publication bias in meta-analysis. J Am Stat Assoc. 2000;95:89-98.

29. Naggara O, Touze E, Beyssen B, Trinquart L, Chatellier G, Meder JF, et al. Anatomical and technical factors associated with stroke or death during carotid angioplasty and stenting: results from the endarterectomy versus angioplasty in patients with symptomatic severe carotid stenosis (EVA-3S) trial and systematic review. Stroke. 2011;42:380-8.

30. Eckstein H-H, Ringleb P, Allenberg J-R, Berger J, Fraedrich G, Hacke W, et al. Results of the Stent-Protected Angioplasty versus Carotid Endarterectomy (SPACE) study to treat symptomatic stenoses at 2 years: a multinational, prospective, randomised trial. Lancet Neurol. 2008;7:893-902.

31. Ederle J, Bonati LH, Dobson J, Featherstone RL, Gaines PA, Beard JD, et al. Endovascular treatment with angioplasty or stenting versus endarterectomy in patients with carotid artery stenosis in the Carotid and Vertebral Artery Transluminal Angioplasty Study (CAVATAS): long-term follow-up of a randomised trial. Lancet Neurol. 2009;8:898-907.

32. Liu ZJ, Fu WG, Guo ZY, Shen LG, Shi ZY, Li JH. Updated systematic review and meta-analysis of randomized clinical trials comparing carotid artery stenting and carotid endarterectomy in the treatment of carotid stenosis. Ann Vasc Surg. 2012;26:576-90. 